\title{
Evaluation of community pharmacists' involvement in public health activities in Nigeria
}

\author{
Kanayo Patrick Osemene $^{1 *}$,Wilson Oyekigho Erhun ${ }^{1}$ \\ ${ }^{1}$ Department of Clinical Pharmacy and Pharmacy Administration, Faculty of Pharmacy, \\ Obafemi Awolowo University, Ile-Ife, Osun State, Nigeria
}

\begin{abstract}
The aims of the study were to identify the types, determine the extent of community pharmacists' involvement, and evaluate the factors influencing their participation in public health activities in Nigeria. The study was a cross-sectional survey of randomly selected 130 registered community pharmacies. Pretested questionnaire was the instrument for data collection. Descriptive and inferential statistics were used to analyse data. Response rate was $94.9 \%$. The study identified 31 types of public health activities which community pharmacists participated in. Their extent of involvement was highest in patient counseling $(4.93 \pm 0.25)$, personal hygiene $(4.90 \pm 0.37)$, maintenance of normal blood pressure $(4.88 \pm 0.32)$, and techniques for using vagina pessaries $(4.85 \pm 0.38)$. Lowest areas of involvement were elimination of smokeless tobacco use (2.27 \pm 1.56$)$, use of seat belts when driving $(2.03 \pm 1.46)$, and the need to live in a safe neighborhood $(1.42 \pm 0.53)$. Inadequate training $(96 \%)$, lack of pharmacists' time (94.6\%), inadequate personnel (92.3\%), lack of patients' time (88.5\%), lack of profit (85.4\%), inadequate space in the pharmacy $(82.3 \%)$ and inadequate patients' information $(69.9 \%)$ significantly influenced their participation. The study concluded that community pharmacists would participate more in public health activities if the identified barriers are reduced.
\end{abstract}

Keywords: Community pharmacists. Pharmacists. Counseling. Public Health. Nigeria.

\section{INTRODUCTION}

The emerging role for community pharmacists include the provision of public health services. However, their knowledge in such public health activities in Nigeria, is not well known because there is little information on the extent of their involvement. Pharmacists are trained in Nigeria as health care professionals who are authorized to import, export, mix, compound, prepare, dispense, counsel, sell, procure and distribute drugs and poisons (Pharmacists Council of Nigeria, 2004). Their training had been described as essentially product-focused (Erhun, Akintilebo, 2008; Awad, Abahussain, 2010). However, it is important that community pharmacists understand patients' non-medication habits which border on public health issues such as lifestyle, diet, smoking among others. Meanwhile, these public health activities rarely form part

\footnotetext{
*Correspondence: Kanayo Patrick Osemene. Department of Clinical Pharmacy and Pharmacy Administration, Faculty of Pharmacy, Obafemi Awolowo University, Ile-Ife, Osun State, Nigeria. Tel: +234(08) 37161268. E-mail: osemenekanayo@gmail.com
}

of the pharmacy students' curriculum (Erhun, Rahman, 1989) and they require specialized skills that may be lacking given their training and responsibilities.

However, with the increasing level of literacy, demand for better care, and globalization, community pharmacists must somehow update their knowledge in public health activities such as immunization programmes, blood pressure and sugar monitoring, counseling patients on alcohol and tobacco use, diet modification, weight management, and stress reduction (Kotecki, Elanjian, Torabi, 2000). Meanwhile, it is well documented that pharmacists are well suited and are in ideal position to influence the life style practices of patients (Weber, Reed, Kroner, 1989; Kotecki et al., 1998; Dombroski, 1999; Kotecki, Elanjian, Torabi, 2000; Kotecki, Fowler, German, 2000). Studies have also shown that it is difficult to change fundamental and ingrained behavours such as tobacco smoking, alcohol use, even diet modification by a single health professional group (Kotecki, Elanjian, Torabi, 2000; Turkkan, Kaufman, Rimer, 2000). Hence, health 
modification efforts require much time and work, by all health care team (Dombroski, Ferro, 1989).

In developed countries, pharmacists perform roles of health advisers to the general public (Phelan, Jepson, 1980; De Young, 1996). In addition, community pharmacists in England and in the United States had offered smoking cessation services (American Pharmaceutical Association, 1998; Anderson, 1998; Dent, 2007; Sinclair, Bond, Stead, 2008; Brown, 2012; Agomo, 2012) made provision of emergency hormonal contraception, carried out prevention and management of drug abuse, misuse (Strang, 2010; Brown, 2012; Agomo, 2012; Watson, 2009; Watson, 2012) and provided evidence-based healthy eating and lifestyle advice to patients (Brown, 2012; Anderson, 2000; Gordon, 2011) and carried out reduction of systolic blood pressure (Morgado, 2011). All this feat was made against documented evidence in literature that certain barriers such inadequate training, lack of pharmacists' time, inadequate personnel, lack of patients' time, lack of profit, inadequate space in the pharmacy, inadequate patients' information among others influenced community pharmacists' participation in public health services (Kotecki et al., 1998; Kotecki, Elanjian, Torabi, 2000; Awad, Abahussain, 2010).

Nevertheless, it was reported in Benin-City, in Nigeria, that community pharmacists perform pharmaceutical care roles without official acknowledgement (Opara, Arigbe-Osula, 2002). While in Lagos State, Nigeria, it was reported that community pharmacists have not been adequately integrated in the programme of pharmaceutical care (Eniojukan, Adeniyi, 1997). However, a recent study revealed that they are getting more involved and this has improved health outcomes with reduced costs (Soyemi, Hunponu-Wusu, 2015). Hence, the call to broaden community pharmacists' role in public health activities is increasing (Wiedenmayer et al., 2006). Community pharmacies are suitable sites for counseling because they have extended hours of work, frequently come in contact with people, and are widely distributed geographically in advanced countries (Semira, Monalina, 2012).

The specific objectives of the study are to identify various types of public health activities; determine the extent of community pharmacists' involvement in these activities; and evaluate factors influencing their participation in these activities in a state in Nigeria.

\section{MATERIAL AND METHODS}

\section{Study setting}

The study was conducted from November 2015 to June 2016 among registered community pharmacies in Oyo State, Nigeria. Oyo State, is one of the thirty-six states in Nigeria, with a population of about 5.5 million people and it spans an area of 28,454 square kilometers (Oyo State Government, 2015).

\section{Sample size and sample design}

Respondents were drawn from the list of registered community pharmacists (137) in Oyo State as contained in the 2015 Pharmacists' Council of Nigeria official book (Pharmacist Council of Nigeria, 2015). This list served as the sample frame. A sample size of 130 respondents was determined using the formula for sample size determination at a $5 \%$ error and a $90 \%$ response rate (Burns, Bush, 2003). There are thirty-three (33) local government councils in Oyo State which are grouped into three senatorial districts. Stratified random sampling technique was used to select registered pharmacies from each of the three strata.

\section{Questionnaire design and administration}

Questionnaire which was the primary instrument for data collection contained mostly closed ended questions. This survey instrument was adapted from an existing one designed by primary care physicians (Wechsler et al., 1996) with some modifications. The questionnaire consists of two sections. The first section contained demographic variables, such as age, sex, year of qualification, educational qualification, experience, and whether respondents had taken part in any public health activities. The second section contained questions on core issues that bordered on types of public health activities in which the community pharmacists are involved; the extent of their involvement, and factors influencing their participation. Respondents were briefed about the objectives of the study and a written consent to participate in the study was sort before the questionnaires were administered. The research instrument (questionnaires) were self-administered by the researchers by hand to the respondents who were made up of 102 pharmacist staff, 28 pharmacist owners, with various years of practice experiences. In addition, 10 of the pharmacies were located in rural areas, 48 in sub-urban centres, and 72 in urban centres. Thereafter, respondents were asked to tick the types of public health activities they conducted in their pharmacies; indicate the extent of their involvement in such activities in a 5-point Likert scale of Never (1) Rarely (2), Sometimes (3), Often (4), and Always (5). They were further asked to rate the factors influencing their participation in a 
5-point Likert scale as No influence (1), Little influence (2), Moderate influence (3), High influence (4), and Very high influence (5). This was followed by oral interview of 130 superintended pharmacists working in the surveyed pharmacies. The average time for the interview with each pharmacist was 9 minutes. The interview section focused on strategies to improve community pharmacists' participation in public health activities.

\section{Validity and reliability of the research instruments}

The contents of the questionnaire were scrutinized by five public health specialists in the Institute of Public Health, College of Medical Sciences, Obafemi Awolowo University, Ile-Ife. Cronbach's alpha was used to assess the consistency of the entire scale which gave a value of 0.87 . Since all of the items had an alpha above 0.70 , the scale is suitable for analysis with acceptable reliability and all constructs exhibited strong internal reliability. The questionnaires were pre-tested at the pilot stage among six community pharmacists outside the study area. The questionnaires were constructed in simple prose devoid of ambiguity. Thereafter, comments, suggestions and corrections made by the respondents were incorporated in order to improve the quality of the questionnaire. The results from the pre-tested questionnaire were used to make corrections where appropriate.

\section{Model specification}

In order to evaluate the factors influencing community pharmacists' participation in public health activities, a model which captured some explanatory variables from literature that were considered as likely barriers to community pharmacists' involvement in public health activities, was formulated. Other variables not explicitly included in the mode were captured in the error term.

$\mathrm{CPPH}=\mathrm{f}(\mathrm{LPT}, \mathrm{LPAT}, \mathrm{LT}, \mathrm{LS}, \mathrm{LTR}, \mathrm{LPS}, \mathrm{GB}, \mathrm{LP}, \mathrm{LF}$,

LI.........Ut)

The explicit form of equation (1) above is represented as follows

$\mathrm{CPPH}=\beta_{\mathrm{O}}+\beta_{1} \mathrm{LPT}+\beta_{2} \mathrm{LPAT}+\beta_{3} \mathrm{LT}+\beta_{4} \mathrm{LS}+\beta_{5} \mathrm{LTR}+$

$\beta_{6} \mathrm{LPS}+\beta_{7} \mathrm{~GB}+\beta_{8} \mathrm{LP}+\beta_{9} \mathrm{LF}+\beta_{10} \mathrm{LI},+\mathrm{Ut}$

Equation 2 can also be expressed in the log form as

$\mathrm{CPPH}=$ Logit $\mathrm{y}_{-}$bin $\mathrm{x}_{1} \mathrm{x}_{2} \mathrm{x}_{3} \mathrm{x}_{4} \mathrm{x}_{5} \mathrm{x}_{6} \mathrm{x}_{7} \mathrm{x}_{8} \mathrm{x}_{9} \mathrm{x}_{10}$ where $\mathrm{y}$ is the dependent variable and $\mathrm{x}_{1} \ldots \mathrm{x}_{10}$ are the independent variables;

\section{Hypothesis of the study}

Using equation (3) the hypothesis below is presented in the null form as

$\mathrm{H}_{\mathrm{o}}$ : Logit $\mathrm{y}_{\text {_b bin }} \mathrm{x}_{1} \mathrm{x}_{2} \mathrm{x}_{3} \mathrm{x}_{4} \mathrm{x}_{5} \mathrm{x}_{6} \mathrm{x}_{7} \mathrm{x}_{8} \mathrm{x}_{9} \mathrm{x}_{10}=0$ and

$\mathrm{H}_{1:}$ Logit $\mathrm{y}_{-}$bin $\mathrm{x}_{1} \mathrm{x}_{2} \mathrm{x}_{3} \mathrm{x}_{4} \mathrm{x}_{5} \mathrm{x}_{6} \mathrm{x}_{7} \mathrm{x}_{8} \mathrm{x}_{9} \mathrm{x}_{10} \neq 0$

The apriori expectation based on information gleaned from the literature, is that variables $x_{1}, x_{2}, x_{3}$, $\mathrm{x}_{4}, \mathrm{x}_{5}, \mathrm{x}_{6}, \mathrm{x}_{8}, \mathrm{x}_{9}$, and $\mathrm{x}_{10}$ are likely to affect community pharmacists' participation in public health activities while variable $\mathrm{x}_{7}$ is very unlikely to have any effect.

Variables in equation (2), are expressed as:

$\mathrm{CPPH}=$ Community pharmacist participation in public health activities.

LPT $=$ Lack of pharmacists' time $\left(\mathrm{x}_{1}\right)$

LPAT $=$ Lack of patients' time $\left(\mathrm{x}_{2}\right)$

$\mathrm{LT}=$ Lack of training $\left(\mathrm{x}_{3}\right)$

$\mathrm{LS}=$ Lack of space in the pharmacies $\left(\mathrm{x}_{4}\right)$

LTR $=$ Lack of patients' trust on ability of pharmacists

$\left(\mathrm{x}_{5}\right)$

LPS $=$ Lack of personnel $\left(\mathrm{x}_{6}\right)$

$\mathrm{GB}=$ Gender $\operatorname{Bias}\left(\mathrm{x}_{7}\right)$

$\mathrm{LP}=$ Lack of Profit $\left(\mathrm{x}_{8}\right)$

$\mathrm{LF}=$ Lack of Funds $\left(\mathrm{x}_{9}\right)$

$\mathrm{LI}=$ Lack of Information $\left(\mathrm{x}_{10}\right)$

$\beta_{1-} \beta_{10}=$ Regression coefficients of the variables

$\beta_{0}=$ Constant term $/$ Slope or intercept

$\mathrm{Ut}=$ Stochastic error term

\section{Data analysis}

Data was analyzed with descriptive statistics using SPSS version 18 for windows. Arithmetic means were presented in the results for completeness. Ordered Probit regression analysis was used to evaluate factors influencing community pharmacists' participation in public health activities based on responses from the 5-point Likert scale in the questionnaire. The robustness of the model was determined based on the values of Pseudo R2, and Prob $>$ chi2 at $p<0.001$ level of significance.

\section{Ethical consideration}

Ethical approval for the study number AD/13/ 479/1051 was obtained from Ministry of Health, Department of Planning, Research and Statistics Division, 
Oyo State Research Ethical Review Committee, Ibadan, Nigeria.

\section{RESULTS}

A total of 130 questionnaires were harvested and analyzed. The community pharmacists mean age and experience (as practitioners) were $30.97 \pm 9.99$ years and $8.78 \pm 0.42$ years respectively. Most of the community pharmacists $(77.7 \%)$ had less than 10 years on the job experience. There were more males than females. Most of the community pharmacists $102(78.5 \%)$ were on paid employment. Only few of them $(21.5 \%)$ were owners of their respective shops. The majority of the pharmacists $126(96.9 \%)$ had first degrees in Pharmacy in terms of academic qualification. More than half $(55.4 \%)$ of the community pharmacists had their practice locations in the urban areas while $36.9 \%$ had theirs in sub-urban setting. The demographic characteristics of respondents are presented in Table I. All the community pharmacists indicated that they participate in 31 types of public health activities especially those related to drug and medication use as presented in Table II.

However, some of them were not so much involved in activities that had to do with personal health-related behavours which are presented in Table III. Means were used for completeness and also to draw clear cut distinctions between the values obtained from a 5-point Likert scale. The degree of involvement of the community pharmacists in non-drug related activities were below average of 2.5 on a 5-point Likert scale in three distinct areas namely, avoiding the use of tobacco (smokeless) $2.27 \pm 1.56$, need to use seat belts while driving or riding a car $2.03 \pm 1.46$, and the need to live in a safe neighborhood $1.42 \pm 0.53$.

Factors that influenced community pharmacists' participation in public health activities in the course of their daily practice were: lack of adequate training (96\%), lack of pharmacists' time (94.6\%), lack of adequate personnel (92.3\%) and lack of patients' time (88.5\%), among others. Only gender bias had a value of 1.39 as presented in Table IV.

Results from the Ordered Probit Regression showed that ten variables were identified as barriers to community pharmacists' participation in public health activities. Gender bias, influenced community pharmacists' participation the least and was not significant $(p<0.45)$. All other variables significantly had tremendous influence as shown in Table V.

Furthermore, results from the oral interview revealed that $56(43 \%)$ of the community pharmacists
TABLE I - Characteristics of community pharmacists $(\mathrm{N}=130)$

\begin{tabular}{|c|c|c|}
\hline Demographic Characteristics & Frequency & Percentage \\
\hline \multicolumn{3}{|l|}{ Gender } \\
\hline Male & 112 & 86.2 \\
\hline Female & 18 & 13.8 \\
\hline Total & 130 & 100 \\
\hline \multicolumn{3}{|l|}{ Age (years) } \\
\hline $18-34$ & 90 & 69.2 \\
\hline $35-51$ & 27 & 20.8 \\
\hline $52-68$ & 13 & 10.0 \\
\hline$>69$ & 0 & 0 \\
\hline Total & 130 & 100 \\
\hline \multicolumn{3}{|l|}{ Status in Work Place } \\
\hline Pharmacist (Staff) & 102 & 78.5 \\
\hline Pharmacist(Owner) & 28 & 21.5 \\
\hline Total & 130 & 100 \\
\hline \multicolumn{3}{|l|}{ Qualification in Pharmacy } \\
\hline B. Pharm & 124 & 95.4 \\
\hline Pharm D & 2 & 1.5 \\
\hline MPharm & 4 & 3.1 \\
\hline Total & 130 & 100 \\
\hline \multicolumn{3}{|l|}{ Experience as practitioners (years) } \\
\hline$\leq 10$ & 101 & 77.7 \\
\hline$>10$ & 29 & 22.3 \\
\hline Total & 130 & 100 \\
\hline \multicolumn{3}{|l|}{ Location of Pharmacy } \\
\hline Rural & 10 & 7.7 \\
\hline Suburban & 48 & 36.9 \\
\hline Urban & 72 & 55.4 \\
\hline Total & 130 & 100 \\
\hline
\end{tabular}

believed that training other personnel in the pharmacies to handle pharmacy-based activity (task- shifting) such as dispensing of drugs would free more time for pharmacists to engage more in public health services. About 70(53.8\%) of the community pharmacists were of the opinion that reconstructing the pharmacies to create more space for patient counseling would encourage them to participate more in public health services. Also, $112(86.2 \%)$ of the community pharmacists were of the opinion that access to patients' file would assist in understanding patients' medication profile and which could be vital in rendering quality public health services. Meanwhile, 101(77.7\%) believed that if people are aware of the extended services (public health) rendered by community pharmacists, 
TABLE II - Types of public health activities undertaken by respondents

\begin{tabular}{|c|c|c|c|}
\hline No & PERSONAL HEALTH BEHAVIOR ITEMS & Yes & No \\
\hline 1 & Take prescription drugs as prescribed & 130 & Nil \\
\hline 2 & Always use condoms if one has multiple sex partners & 130 & Nil \\
\hline 3 & Eliminate cigarette, pipe, or cigar smoking & 126 & 4 \\
\hline 4 & Eliminate smokeless tobacco use & 50 & 80 \\
\hline 5 & Always use seat belts when driving or riding in a car & 45 & 85 \\
\hline 6 & Take over-the-counter drugs as directed & 130 & Nil \\
\hline 7 & Maintain normal blood pressure & 130 & Nil \\
\hline 8 & Balance the food one eats with physical activity to improve weight & 130 & Nil \\
\hline 9 & Be knowledgeable about drug contents and side effects & 130 & Nil \\
\hline 10 & Maintain normal blood cholesterol level & 130 & Nil \\
\hline 11 & If one drinks alcoholic beverages, do in moderation & 130 & Nil \\
\hline 12 & Choose a diet with plenty of grain products vegetables, and fruits & 130 & Nil \\
\hline 13 & Choose a diet low in fat, saturated fat, and cholesterol & 110 & 20 \\
\hline 14 & Eat a variety of foods & 130 & Nil \\
\hline 15 & Have an annual physical examination for preventive screenings & 92 & 38 \\
\hline 16 & Maintain ideal weight & 130 & Nil \\
\hline 17 & Avoid undue stress & 130 & Nil \\
\hline 18 & Choose a diet moderate in salt and sodium & 130 & Nil \\
\hline 19 & Choose a diet moderate in sugars & 130 & Nil \\
\hline 20 & Engage in aerobic activity three or more times a week & 130 & Nil \\
\hline 21 & Live in a safe neighborhood & 130 & Nil \\
\hline 22 & Regularly practice relaxation techniques & 130 & Nil \\
\hline 23 & Engage in strength training of moderate intensity at least twice a week & 126 & 4 \\
\hline 24 & Educate patients about family planning & 130 & Nil \\
\hline 25 & Educate patients about sexually transmitted disease & 130 & Nil \\
\hline 26 & Personal hygiene & 130 & Nil \\
\hline 27 & Techniques for using vagina pessaries & 130 & Nil \\
\hline 28 & Techniques for using aerosols/inhalers (Asthmatic patients) & 130 & Nil \\
\hline 29 & Environmental sanitation (Fumigation etc) & 130 & Nil \\
\hline 30 & Need for water therapy & 130 & Nil \\
\hline 31 & Use of insecticide treated nets & 130 & Nil \\
\hline
\end{tabular}

more people would be willing to seek such services from community pharmacies.

\section{DISCUSSION}

The major strengths of this study are that it represents a novel effort which assessed non-drug services by community pharmacists as well as the employment of new methodology to evaluate variables that influenced their participation. Study results, would assist health policy makers in re-designing programmes that would extensively utilize the untapped potentials of community pharmacists. However, some notable weaknesses of the study are that only one state was studied using a cross sectional survey. So, results may not be generalized. Views of patients were not sort. Doing so would have enabled the researcher confirm some of the claims of the respondents. A longitudinal study would provide ample opportunity for an interventional study upon which further research could be built. Nevertheless, results from this study would have far reaching effects.

The main findings of the study were the identification 
TABLE III - Extent of participation of respondents in public health activities

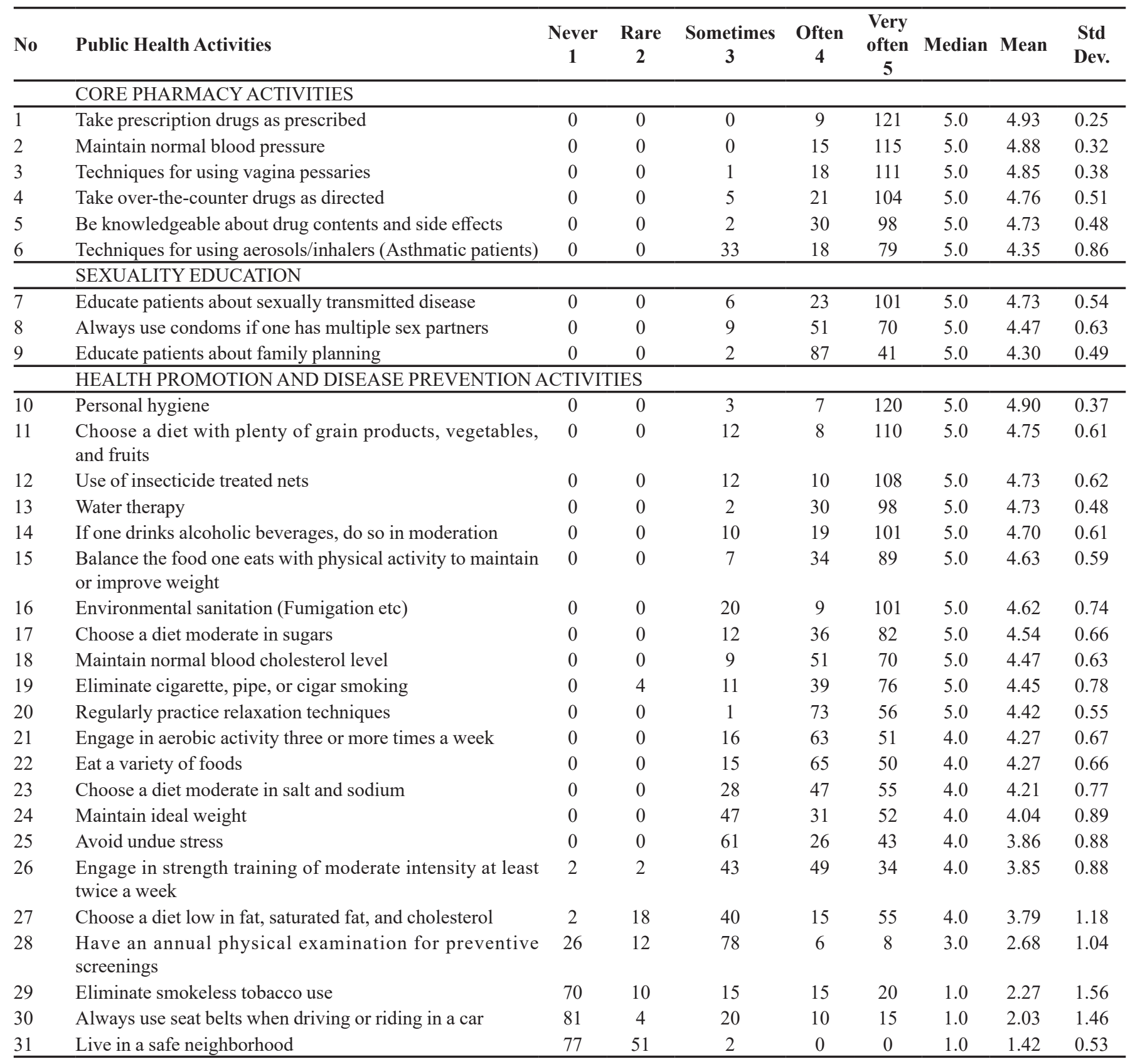

of 31 health public services rendered by community pharmacists, which indicated high level of involvement in pharmacy-based services while some barriers that influenced their participation were inadequate training, pharmacists' time, patients' time, funds, personnel, structure of the pharmacies among others.

Male community pharmacists were more than females and all the pharmacists were on full time employment. Similar results were obtained from studies carried out in the United States and Kuwait (Awad, Abahussain, 2010; Kotecki, Elanjian, Torabi, 2000).
Furthermore, the service area location of the community pharmacies was unevenly distributed because more of the pharmacies were located in the urban areas compared with the once found in the semi-urban and rural areas. This finding is at variance with the results obtained elsewhere (Kotecki, Elanjian, Torabi, 2000). Reason for uneven distribution pattern which was in favour of urban settings could be that urban settings are highly populated and more industrialized.

The participation of community pharmacists in many health-related behaviours shows that they are 
Evaluation of community pharmacists' involvement in public health activities in Nigeria

TABLE IV - Influence of the under-listed variables on community pharmacists' participation in public health activities

\begin{tabular}{llccccccc}
\hline No. & Variables & $\begin{array}{c}\text { No } \\
\text { influence } \\
\mathbf{1}\end{array}$ & $\begin{array}{c}\text { Little } \\
\text { influence } \\
\mathbf{2}\end{array}$ & $\begin{array}{c}\text { Moderate } \\
\text { influence }\end{array}$ & $\begin{array}{c}\text { High } \\
\text { influence }\end{array}$ & $\begin{array}{c}\text { Very high } \\
\text { influence }\end{array}$ & Median & Mean \\
\hline 1 & Lack of pharmacists' time & 0 & 1 & 6 & 20 & 103 & 5.0 & 4.73 \\
2 & Lack of patients' time & 0 & 5 & 10 & 19 & 96 & 5.0 & 4.59 \\
3 & Lack of training & 0 & 1 & 4 & 46 & 79 & 5.0 & 4.56 \\
4 & Lack of space in the pharmacy & 1 & 2 & 20 & 43 & 64 & 4.0 & 4.28 \\
5 & Lack of Patients' trust & 20 & 68 & 11 & 13 & 18 & 2.0 & 2.55 \\
6 & Lack of personnel & 1 & 1 & 8 & 19 & 101 & 5.0 & 4.68 \\
7 & Gender bias & 86 & 40 & 2 & 1 & 1 & 1.0 & 1.39 \\
8 & Lack of profit & 1 & 1 & 17 & 22 & 89 & 5.0 & 4.51 \\
9 & Lack of funds & 24 & 30 & 40 & 9 & 27 & 3.0 & 2.88 \\
10 & Level of information & 1 & 1 & 38 & 23 & 67 & 5.0 & 4.19 \\
\hline
\end{tabular}

TABLE V - Results of Ordered Probit Regression Analysis showing the effect of certain barriers to community pharmacists' participation in public health activities

\begin{tabular}{lccccccc}
\hline $\mathbf{S} / \mathbf{N}$ & Parameters & Coeff. & SE & Z-Score & $\mathbf{P}>|\mathbf{Z}|$ & \multicolumn{1}{c}{ [95\% Conf. Interval] } \\
\hline 1 & Lack of pharm. time & -15.59 & 3.198 & -7.99 & $0.001^{*}$ & 0.20383 & 0.9814 \\
2 & Lack of patients' time & -13.13 & 3.184 & -10.72 & $0.001^{*}$ & -2.2867 & 0.4914 \\
3 & Lack of training & -10.68 & 4.395 & -11.72 & $0.001^{*}$ & -1.4544 & 0.0951 \\
4 & Lack of space & -11.24 & 3.118 & -12.05 & $0.000^{*}$ & -0.4721 & -0.0179 \\
5 & Lack of Patients trust & 16.32 & 3.375 & 10.85 & $0.001^{*}$ & -0.4175 & 1.0559 \\
6 & Lack of personnel & -12.03 & 3.244 & -10.12 & $0.001^{*}$ & -0.4495 & 0.5068 \\
7 & Gender bias & 15.33 & 2.339 & 0.96 & 0.450 & -0.9904 & 0.3395 \\
8 & Lack of profit & -14.40 & 5.472 & -12.97 & $0.001^{*}$ & 0.4784 & 2.3299 \\
9 & Lack of funds & -13.42 & 4.243 & -11.74 & $0.001^{*}$ & -0.8998 & 0.0523 \\
10 & Level of information & 12.22 & 4.444 & 10.48 & $0.001^{*}$ & -1.08562 & 0.6554 \\
\hline
\end{tabular}

*Significant level $\mathrm{P}<0.001$. Number of observations $=130$. LR chi $2(10)=56.96$. Prob $>$ chi2 $=0.0000$. Pseudo R2=0.6898.

beginning to play the much-expanded role which is beyond product-oriented services. This result agrees with the findings of a similar study elsewhere (Soyemi, HunponuWusu, 2015). Community pharmacists participated more in medication use services. This is also in agreement with the finding of a similar study conducted in Indiana United States of America (Kotecki, Elanjian, Torabi, 2000). The high level of involvement of the community pharmacists in teaching patients about proper use of medication could be attributed to the nature of their training (Kotecki, Elanjian, Torabi, 2000). Reasons for their low participation in non-drug health-related behaviour may be caused by lack of official acknowledgement and appreciation of their efforts in performing pharmaceutical care roles (Opara, Arigbe-Osula, 2002). Meanwhile, patients do not consider community pharmacies as primary health care facilities (Al-Wazaify, Albsoul-Younes, 2005; Al-Wazaify et al., 2006).

Prominent factor that influenced the extent of community pharmacists' participation in health education and promotion activities was lack of pharmacists' time. Similar results were obtained elsewhere (Keen, Cervetto, Wilson, 1994; Dunlop, Shaw, 2002; Aquilino et al., 2003; Uema et al., 2008). Since only one full time pharmacist oversaw daily pharmaceutical and administrative operations, workload could be high leaving no freetime for pharmacists to render patient-focused care. If pharmacists had more time, they were likely to participate more in public health activities as gleaned from the Probit logistic analysis. Lack of pharmacists' time was 
compounded by manpower shortage. Task shifting could help reduce pharmacists' workload. In addition, less critical activities such as costing of prescribed medications, filling of prescriptions, administrative operations among others could be handled by non-pharmacist staff. If need be more hands could be hired to address the issue of manpower shortage. As a result, this will make more time to be available for the pharmacists to attend to the patients.

Secondly, the lack of patients' time was significant. Similar result was obtained by Awad, Abahussain (2010). Generally, patients spend quality time with physicians during hospital visits. Therefore, by the time they get to the pharmacies to fill prescriptions, they would have been tired and eager to go home. Creating a more conducive room in the pharmacies such as furnishing a part of the pharmacy with comfortable seats where patients can relax to read newspapers, magazines watch televisions, and even listen to soft tuned music in an air conditioned environment could lessen the stress experienced by patients. This could make patients to endure a little longer while their prescriptions are being filled. Ideally, community pharmacies should be structured to provide comfort and some degree of privacy for patients. This could improve patients' counseling. However, since most community pharmacists carry out their practice in rented apartments, it becomes difficult to redesign pharmacies the way they should be. So, lack of space for patient counseling remains a formidable barrier (Awad, Abahussain, 2010; Kotecki, Elanjian, Torabi, 2000). Even when the will to restructure pharmacies is there, inadequate funds could constitute another challenge.

Lack of adequate training of pharmacists had significant influence on their extent of participation in public health services. In Nigeria, public health activities, rarely form part of the pharmacy curriculum, hence the requisite skill maybe inadequate (Opara, ArigbeOsula, 2002). Possible alternatives to this barrier are for community pharmacists to engage in continuing education programmes in order to gain more knowledge and skills in public health issues. The continuing education could be receiving regular newsletters, participation in public health lectures, conferences, workshops, seminars and receiving distant learning packages (Kotecki, et al.; 2000; Awad, Abahussain, 2010).

In addition, perceived fear that patients will not be willing to pay additional charges for non-drug related health services could discourage community pharmacists from undertaking non-drug related services. This finding is in agreement with results obtained in a similar study conducted in Malaysia (Semira, Monalina, 2012). However, to overcome the barrier of patients' unwillingness to pay for non-drug related health services rendered by community pharmacists, the later should make the patients to know and experience the benefits of rendering such extended roles in terms of outcomes and at same time bring to the knowledge of the patients such added services which the patients did not expect. Once patients are aware of such services they will be willingly to pay for them.

Lack of patients' trust on the ability of pharmacists to offer non-drug health related services was another barrier. This result corroborates the findings of a similar study conducted in Kuwait (Awad, Abahussain, 2010). Pharmacists expanded roles are not clearly defined, recognized, and sufficiently promoted by health agencies and other healthcare professionals (American Pharmaceutical Association, 1998). If lack of trust by patients decreases, there will be an increase in probability that more patients would seek non-drug health related services from community pharmacies. Patients' trust about the pharmacist could be enhanced through advocacy by educating patients about the emerging roles of the pharmacists in health education and promotion activities. Once patients are aware of such roles and community pharmacists' capability of effectively rendering extended services that would improve health outcomes their trusts in community pharmacists would be enhanced.

Lack of access to patients' data, was a major challenge. In Nigeria, community pharmacists do not have access to patients' medication data or profile. Without a reliable and documented patients' data, it would be difficult to determine other forms of pharmaceutical services that patients will need. The development of effective collaborations by community pharmacists with the physicians, nurses, and other health care workers could be of immense help in this regard. Such collaboration could foster healthy relationship among the health care team and perhaps facilitate free information flow about patients and increase access to patients' data.

Gender bias had no significant influence on community pharmacists' participation in public health activities. This result validates our apriori expectation. Moreover, in Nigeria there are no laws restricting access to medical care based on sex.

\section{CONCLUSION}

The study identified thirty-one types of public health services which community pharmacists were involved in. These activities were mainly on proper use of drugs. The extent of their participation was high. Factors that significantly influenced their participation were lack of adequate training, lack of pharmacists' time, manpower 
shortage, lack of patients' time, lack of patients' trust on the ability of pharmacists to render public health activities, lack of profit, lack of patient data, lack of funds, and inadequate space in the pharmacies. Gender had no significant contribution to the extent of involvement in public health activities. The study recommends that community pharmacists should:

1. Employ or train more hands to assist them in handling other activities (task shifting) so that more time would be made available for patient counseling etc.;

2. Restructure the pharmacies in order to create adequate space conducive for services in public health issues;

3. Collaborate more with other health care professionals so that patients' data could be accessed; and

4. Let their immediate community know about their public health activities, so that the public should trust their ability to render such services.

\section{ACKNOWLEDGEMENTS}

We are grateful to the respondents

\section{CONFLICT OF INTEREST}

The authors have no conflict of interest to declare.

\section{FUNDING}

No grant or fund was received from any agency be it public, commercial or not-for-profit organization to under-take this study.

\section{REFERENCES}

Agomo C. The role of community pharmacists in public health. A scoping review of literature. J Pharm Hlth Serv Res. 2012;3(1):25-33.

Al-Wazaify M, Albsoul-Younes A. Pharmacy in Jordan. Am J Health-Syst Pharm. 2005;62(23):2548-2551

Al-Wazaify M, Matowe L, Albsoul-Younes A, AL-Omran O. Pharmacy in Jordan, Saud Arabia, and Kuwait. Am J Health-Syst Pharm. 2006;70(1):18.

American Pharmaceutical Association. Pharmacist Practice Activity Classification Version 1.0 1998. [Cited 2016 May 10]. Available from: .
Anderson C. Health Promotion by community pharmacists: realities and constraints. J Soc Adm Pharm. 1998;15(1):11-21.

Anderson C. Health promotion in community pharmacy: the UK situation. Patient Educ Couns. 2000;39(2-3):285-289.

Aquilino ML, Farris KB, Zillich AJ, Lowe JB. Smoking cessation services in Iowa community pharmacies. Pharmacother. 2003;23(5):666-673.

Awad A, Abahussain E. Health Promotion and Education activities of Community Pharmacists in Kuwait. Pharm World Sci. 2010;32(2):146-153.

Brown DPJ. Review of services provided by pharmacies that promote healthy living. Int J Clin Pharm. 2012;34(3):399-409.

Burns AC, Bush RF. Marketing research: online application. $4^{\text {th }}$ ed. Pearson Prentice Hall; 2003.

De Young M. Research on the effects of pharmacist-patient communication in institutions and ambulatory care sites, 19691994. Am J Health-Syst Pharm. 1996;53(11):1277-91.

Dent LA. Tobacco interventions delivered by pharmacists: A summary and systematic review. Pharmacotherapy. 2007;27(7):1040-1051.

Dombroski SR. Pharmacists counseling on nutrition and physical activities parts of 2: understanding current guidelines. J Am Pharm Assoc. 1999;39(4):479-491.

Dombroski SR, Ferro LA. Pharmacist counseling on nutrition and Physical activity part 2of 2: Helping Patients make changes. J Am Pharm Assoc. 1989;39(5):613-627.

Dunlop JA, Shaw JP. Community Pharmacists perspectives on pharmaceutical care implementation in New Zealand. Pharm World Sci. 2002;24(6):224-230.

Erhun WO, Akintilebo TA. Mandatory Continuing Professional Development Programme for Pharmacists in Nigeria. Nig. J Pharm. 2008;41(3):33-41.

Erhun WO, Rahman AW. Comparative appraisal of the pharmacy curriculum at a Nigerian University. J Soc Adm Pharm. 1989;6(2):92-98.

Eniojukan JF, Adeniyi A. Community Pharmacists and primary health programmes. Nig J Pharm. 1997;28(2):21-24. 
Gordon JWM. Lightening the load? A systematic review of community pharmacy-based weight management interventions. Obesity reviews: J Inter Assoc Study Obes. 2011;12(11):897911.

Keene J, Cervetto S, Wilson A. Health promotion in the community pharmacy. Pharm J. 1994;252:408-9.

Kotecki JE, Elanjian SI, Torabi MR, Clark JK. Pharmacists concerns and suggestions related to the sale of tobacco and alcohol by pharmacies. J Community Health. 1998;23(5):359370 .

Kotecki JE, Fowler JB, German TC. Kentucky pharmacists' opinions and practices related to the sale of cigarettes and alcohol in pharmacies. J Community Health. 2000;25(4):343355 .

Kotecki JE, Elanjian SI, Torabi MR. Health promotion beliefs and practices among pharmacists. J Am Pharm Assoc. 2000;40(6):773-9.

Morgado MP. Pharmacist's intervention to enhance blood pressure control and adherence to antihypertensive therapy: review and meta-analysis. Am J Health-Syst. Pharm. 2011;68(3):241-253.

Opara AC, Arigbe-Osula EM. Evaluation of community pharmacists' involvement in primary health care. Trop J Pharm Res. 2002;1(2):64-74.

Oyo State Government Past and Present. Produced by Oyo State Ministry of Information, Youths Sports and Culture, Ibadan; 2015. p. 14-23.

Pharmacists Council of Nigeria. Pharmacy and Drug Laws in Nigeria. Resolution and Role of the Pharmacist in Supporting the WHO Reserved Drug Strategy. Published by the Pharmacists Council of Nigeria: Abuja; 2004.

Pharmacist Council of Nigeria. List of Registered Pharmacies in Nigeria. Compiled by the Pharmacists Council of Nigeria. Abuja; 2015.

Phelan MJ, Jepson MH. The advisory role of general practice pharmacist. Pharmaceut J. 1980;223:238.

Semira AB, Monalina AH. Knowledge, perception, practice and barriers of breast cancer health promotion activities among community pharmacists in two districts of Selanger, Malaysia. Asian Pacific J Cancer Prev. 2012;13(9):4427-4430.
Sinclair HK, Bond CM, Stead LF. Community pharmacy personnel interventions to smoking cessation. Cochrane Library; 2008.

Soyemi OI, Hunponu-Wusu OO. Knowledge, attitudes and participation of community pharmacists in Lagos State, Nigeria towards Primary Health Care. J Pub Health Epid. 2015;7(1):1519.

Strang JHM. Impact of supervision of methadone consumption on deaths related to methadone overdose (1993-2008): analysis using OD4 index in England and Scotland. Br Med J. 2010;341:c4851.

Turkkan JS, Kaufman NJ, Rimer BK. Transdisciplinary tobacco use research centres: a model collaboration between public and private sectors. Nicotine Tob Res. 2000;2:9-13.

Uema SA, Vega EM, Armando PD, Fontana D. Barriers to pharmaceutical care in Argentina. Pharm World Sci. 2008;30(3):211-215.

Watson MC. The feasibility of providing community pharmacybased services for alcohol misuse: a literature review. Int J Pharm Pract. 2009;17(4):199-205.

Watson THC. Pharmacists and harm reduction: A review of current practices and attitudes. Can Pharm J. 2012;145(3):124127.

Wechsler H, Leivine S, Idelson RK, Schor WL, Coakley E. The physician's role in health promotion revisited-a survey of primary care practitioners. N Engl J Med. 1996;334(15):996998.

Weber MP, Reed MT, Kroner SE. Health Promotion and Disease Prevention: The Pharmacist's Role. Am Pharm. 1989;29(10):3739.

Wiedenmayer K, Summers RS, Mackie CA, Gous AGS, Everard M, Tromp D. Developing Pharmacy Practice. A Focus on Patient Care. Handbook. Geneva: World Health Organization; 2006.

Received for publication on $06^{\text {th }}$ August 2017 Accepted for publication on $23^{\text {th }}$ January 2018 